\title{
Neurofibromatosis 1 Diagnosed in Mother Only after a Follow-up of Her Daughter
}

\author{
Vojtech Kunc ${ }^{1}$ Hari Venkatramani ${ }^{2} \quad$ S. Raja Sabapathy ${ }^{2}$
}

\author{
${ }^{1}$ Department of Anatomy, Second Faculty of Medicine, Charles \\ University, Prague, Czech Republic \\ ${ }^{2}$ Department of Plastic Surgery, Hand and Reconstructive \\ Microsurgery, Ganga Hospital, Coimbatore, Tamil Nadu, India
}

Indian J Plast Surg 2019;52:260-260

Dear Sir,

We present the case of a mother and daughter diagnosed in our unit with neurofibromatosis 1 (NF-1). The diagnosis was first made in our Plastic Surgery Department, and, surprisingly, the daughter was diagnosed first. We find it both interesting that the mother and daughter have very different course of disease and disturbing that the diagnosis was not made earlier, which could have led to better results with a significantly smaller emotional burden on the patient.

A 4-year-old girl (referred to as a daughter) was brought to our unit by her father with history of difficulty in walking on her left leg and foot. Anterior bowing of her left leg was noticed during birth. She has been feeling pain in the left leg during walking for $1 \frac{1}{2}$ years. Physical examination revealed a left antalgic gait and multiple café-au-lait spots. Radiographs of the tibia showed pseudarthrosis type $\mathrm{V}$ (Boyd classification), which was treated by the segmental resection of the tibia and vascularized free fibula flap.

Two years later, the mother of the aforementioned patient came to our unit with her for a follow-up. During examination, she complained of a swelling on her right inner arm that had been continuously growing for the past 15 years. Six months ago, pain was noticed, and it was progressively increasing since then. Multiple café-au-lait spots were also noted. The biopsy report stated a malignant peripheral nerve sheath tumor.

The mother and daughter both fulfilled five criteria-both had six or more café-au-lait spots according to measurements mentioned in (-Table 1), Lisch's nodules, freckles in axillary regions, and both had a first-degree relative with NF-1. Moreover, the daughter had an osseous lesion, and the mother more than two neurofibromas.

In most cases, the patient will be referred to a plastic surgeon to seek treatment for already diagnosed NF-1. However, this case shows that it can be diagnosed by a plastic surgeon as well.

Our understanding of NF-1 has increased significantly during the past decade. Detailed guidelines exist, and some countries even have specialized centers for neurofibromas and can diagnose most patients during childhood. ${ }^{1,2}$ Nevertheless, special attention is required in countries where
Address for correspondence Dr. S. R. Sabapathy, MS, MCh(Plast), DNB(Plast), Ganga Hospital, 313, Mettupalayam Road, Coimbatore 641043, Tamil Nadu, India (e-mail: rajahand@gmail.com).

Table 1 Seven features of NF-1 stated by NIH Consensus Development Conference ${ }^{1,2}$

\begin{tabular}{|c|l|}
\hline 1 & $\begin{array}{l}\text { Six or more cafe-au-lait spots } \geq 5 \mathrm{~mm} \text { in longest } \\
\text { diameter in prepubertal patients, with } 15 \mathrm{~mm} \text { in } \\
\text { longest diameter in postpubertal patients }\end{array}$ \\
\hline 2 & $\begin{array}{l}\text { Two or more neurofibromas of any type or } 1 \text { plexiform } \\
\text { neurofibroma }\end{array}$ \\
\hline 3 & Freckling in the axillary or inguinal regions \\
\hline 4 & Optic glioma (optic pathway glioma) \\
\hline 5 & Two or more Lisch's nodules (iris hamartomas) \\
\hline 6 & $\begin{array}{l}\text { A distinctive osseous lesion, such as sphenoid wing } \\
\text { dysplasia or cortical thinning of the cortex of long } \\
\text { bones, with or without pseudarthrosis }\end{array}$ \\
\hline 7 & $\begin{array}{l}\text { First-degree relative (parent, sibling, or child) with NF-1 } \\
\text { according to criteria }\end{array}$ \\
\hline
\end{tabular}

Abbreviations: NF-1, neurofibromatosis 1; NIH, National Institutes of Health.

genetic counseling is not very common as the understanding of NF-1 among clinicians is still poor even though it is a relatively common disease with a prevalence $1: 3,000$. A basic understanding of the diagnostic process among plastic and orthopedic surgeons could lead to earlier diagnoses, better results, and less emotional stress on the patient.

\section{Disclosure}

The authors have no financial interest to declare in relation to the content of this article.

This paper was not presented on any meeting.

\section{Conflict of Interest}

None declared.

\section{References}

1. National Institutes of Health Consensus Development Conference. Neurofibromatosis. Conference statement. Arch Neurol 1988;45(5):575-578

2. Hersh JH; American Academy of Pediatrics Committee on Genetics. Health supervision for children with neurofibromatosis. Pediatrics 2008;121(3):633-642 